pressures and pulse-rates were measured and used for computing the Crampton index of vasomotor tone, and the electrical conductivity of the skin was measured. From experiments carried out under control conditions it was concluded that changes in the Crampton index were related to changes in thermal stress. The numerical value of the index declined as the women subjects felt hotter and more fatigued. It has been found that, until the skin becomes visibly wet with sweat, there is a linear relation between its electrical conductivity and the number of active sweat glands.

Dr. A. Parker spoke on house heating and atmospheric pollution. Domestic chimneys are responsible for a million tons of smoke a year and for a million tons of sulphur dioxide, and the solution to the problem lies in the use of smokeless fuels-gas, electricity and coke-in proper balance. Problems of economics as well as fuel technology arise here. Only one day's supply of gas can be stored, and it is impracticable to store electricity on a large scale, so that the main stand-by must necessarily be solid fuel. Coke should not be regarded as a surplus product arising from the manufacture of gas, but rather the needs for coke and for gas should be taken into account together. People should regard coke as a valuable smokeless fuel in its own. right, and not merely as partly-used coal. Dr. Parker thinks the problem is not insoluble. In Britain, he said, people insist on having open fires, and such fires are perhaps desirable in this climate, but there is no prospect of burning bituminous coal in such fires without creating smoke. When convective methods of heating are used, people tend to demand an air temperature about $8^{\circ} \mathrm{F}$. higher than with radiant heating, with consequently greater fuel consumption. It might be suggested that district heating should be extended; but with this form of heating it is usual to make a weekly charge for heat without reference to the quantity used, so that the consumer has no incentive to practise economy, with the result that the amount of fuel used per house with district heating is greater than with open fires.

Mr. J. B. Dick spoke about factor's of design and construction affecting heating and ventilation in dwellings. It is the experience of the Building Research Station that, with an internal flue, about 40 per cent of the heat from an open fire is delivered into the house, and with such a fire an acceptable standard of comfort can be obtained at lower cost than with a hot-water radiator. It is important not to provide a heating system that will be too costly for the householder to maintain.

Recent improvements in construction were doscribed. An 11-in. cavity wall with a foamed-slag inner leaf has an overall thermal transmittance of only two-thirds that of an 11 -in. cavity wall entirely of brick, and a transmittance of less than half that of a solid 9-in. brick wall. The use of glass wool for roof insulation was described. Besides reducing fuel consumption to maintain a given air temperature, good thermal insulation also raises the temperature of the inner surface of external walls and thus enhances comfort. 'Temperature gradients can be caused by the convection from cold walls or windows. Better insulation of the walls and tubular heaters beneath windows can cure this. Floor heating also helps to prevent these gradients, and when heating is by the admission of warmed air this should enter at low level and air exits should be placed at high level.

The temperatures maintained in houses depend not only on the preferences of the occupants, but also on the cost. Thus, in some experimental houses the temperatures in the living-rooms at 9 p.m. commonly averaged $65^{\circ} \mathbf{F}$., but during cold weather the figure fell to $60^{\circ} \mathrm{F}$. It was evident that the householders would not pay for the heat then required to maintain a temperature of $65^{\circ} \mathrm{F}$. With improved insulation some of the potential saving of fuel may not be realized because higher temperatures are likely to be maintained by the occupants. Hence emphasis must be placed on better insulation without increased capital cost. One way in which this can be achicved is by use of the foamed-slag inner leaf in cavity walls.

Dr. C. G. Douglas, who opened the discussion, believes that the problems of heating and ventilating factories and offices are easier than those relating to houses. Instrumental methods have been devised for the study of the indoor environment, and the difficulties that now arise are mainly economic. It is important to consider what could be done to provide comfortable warmth for aged people with limited resources. The high cost of coal has driven many people to use kerosene for supplementary heating.

\section{AHMEDABAD TEXTILE INDUSTRY'S RESEARCH ASSOCIATION}

\section{By DR. VIKRAM A. SARABHAI \\ Director}

$\mathrm{O}^{\mathrm{N}}$ April 10, Mr. Jawaharlal Nehru, Prime Minister of India, opened the new laboratory building at Navrangpura, Ahmedabad 9, of the Ahmedabad Textile Industry's Research Association, the foundation stone of which was laid in November 1950 by the late Sardar Vallabhbhai Patel, Deputy Prime Minister of India. The Association is modelled on the same lines as the research associations in Great Britain, and this constitutes the first enterprise of its kind in which industry and the Government of India have co-operated in the field of research. The past five years have witnessed the growth in India of a chain of national laboratories inspired by Sir Shanti Bhatnagar, director of the Council of Scientific and Industrial Research, and Sir Shanti has also been actively associated with the growth and development of the new Association at Ahmedabad, which is the second largest centre of the textile industry in India.

The idea of establishing a textile research laboratory maintained by the joint effort of industry and the Government of India was first conceived by the Ahmedabad Millowners' Association in 1944, and the Ahmedabad Textile Industry's Research Association was registered in December 1947. Its seventy "one founder-members made an initial contribution of approximately $£ 370,000$ towards the initial expenses, and the Government of India gave approximately $£ 145,000$. The recurring expenses are shared equally by industry and the Government. Recently, membership of the Association was thrown open to mills all over India, and co-operative research is now increasingly made use of by the premier industry of the country.

The laboratorios are on the Gujarat University campus and consist of a multi-story central block, covering an area of 100,000 sq. ft., which accommodates the library, offices and laboratories of the various research divisions, the administrative offices, the stores and precision workshop, and the services in a basement. The block is connected at one end to 
a single-story building which houses the pilot mill. At the other end are situated a cafeteria and an auditorium. The pilot mill is equipped with complete machinery for spinning, weaving and chemical processing, with facilities for experimenting under a variety of conditions. The physical testing laboratory has a comprehensive range of modern testing instruments for fibres, yarns and fabrics. The unit plant laboratory has a number of laboratory models of standard dyeing and printing machines and will also be equipped in the near future for some of the unit processes of chemical engineering. The entire building is air-conditioned for comfort, except for the physical testing room and the pilot mill, which have separate air-conditioning to maintain required constant temperatures and humidities.

Even though the laboratory building has only now been completed, the work of the Association commenced about five years ago in the Science College at Ahmedabad with the recruitment of staff for statistics, chemistry, physics and psychology. Recognizing the increasing importance of industrial psychology and the science of management, the Association decided from the outset to include these in its organization. It was also felt that during its early years, the Association should commence its work with the utilization of existing scientific knowledge and apply this for the immediate benefit of the industry. Emphasis was deliberately placed on operational research aimed at standardization and rationalization of existing processes and work methods, and on applied research designed to introduce developments of practical use to the industry. This was done with the view of fostering scientific consciousness among those who work in the industry and creating confidence in the practical utility of applying the scientific method to the problems of industry.

Operational and applied research is generally carried out in the mills in collaboration with the technical staff of the mills. At all stages of the experiment, critical evaluation is continuously done in frequent conferences among the staff of the Association and in discussions with mill management and technicians. After the successful completion of experimental studies in two or three mills, the results are published in the form of research notes. This, however, constitutes only half the work. Successful inplementation and translation of the benefits to industry are equally important tasks on which the Association has placed great emphasis. It believes it to be its duty to demonstrate without cost to its members, in their own mills, the full utility of imple. mentation of its research work. However, every effort is made to ensure that its resources are not diverted to routine operations which legitimately fall within the domain of individual mill management. When circumstances require that the Association should be engaged in routine services, separate units are created for this purpose. In this way the Association operates routine physical and chemical testing laboratories and provides servicing and supervision of quality control, training-within-industry programmes and other management techniques to industry. The cost of these units is defrayed by the mills which participate in these benefits.

To-day the Association has eight Divisions dealing with Physics, Chemistry, Statistics, Psychology, Liaison, Technology, Library and Documentation and Administration.

Pending the establishment of the Textile Technology Division, the Physies Division mainly con- centrated during the initial years on problems of spinning. It modified the micro-sample spinning technique developed in other laboratories so that a sample of one pound of cotton may be spun in a short time on the usual mill spinning plant under mill conditions of speeds, settings, etc. The yarns produced by this small-sample spinning method check well in lea strength with the yarns produced by the normal large-scale mill processes. This technique has also been used for investigating the application of various spinning aids and in the investigation of blending of cottons. A study has been undertaken of the fibre length distribution and the evenness of the material under process at various stages in spinning. This Division has a well-equipped optics laboratory in which work is being done at present on a study of the adsorption of dyes and other chemicals on the surface of textile materials. Attempts are also being made to correlate the degree of orientation of mercerized fibres with lustre and to use the X-ray technique for determining the degree of mercerization. A modest beginning in instrumentation and electronic developments has been made by creating a separate section for these in the Physies Division.

The Chemistry Division started initially with a survey of the various textile chemical processes in the member mills of the Association and the determination of optimum conditions for these processes. A detailed study of sizing practice was made, and simple experimental methods for the evaluation of sizing materials and methods were demonstrated to mills. Extensive studies were also made to assess the value of tamarind kernel-powder, an indigenous material, as a sizing material for cotton warps for both bleached and grey sorts., Suitable modifications were worked out to overcome the objectionable reddish colour of this material. A long-term fundamental study of sizing has been planned, and work on this programme has been started very recently. Attempts are also being made to produce improved finishes; using so far as possible indigenous materials. Three such processes have been worked out on a laboratory scale and will shortly be tried in mills on a pilot-plant scale. In order to explore the possibilities of mercerizing textiles made from Indian cottons, an extensive study has been undertaken on a comparison of the mercerization of different cottons (Indian, African, American and Egyptian) in fibre, yarn and cloth stages. The Chemistry Division also maintains a technical service which undertakes investigation of a number of production problems from the chemical processing departments of member mills.

The Textile Technology Division has been created this year with the arrival of machinery for the pilot mill. Among the problems that are being taken up for investigation are (1) the relationship between individual fibre characteristics of a blend and the properties of the yarn and its weavability, and (2) the effect of yarn conditioning, atmospheric conditions and loom tensions on weavability.

The main effort of the Statistics Division has been directed to the development and application of quality control methods to the textile industry. With the Association's collaboration, quality control sections have been established in about twenty-four mills, and statistical methods have been applied by these sections to improve operational characteristics such as breakages, uniformity, waste, damages and efficiency. The Statistics Division has also carried out a number of short-term experiments in spinning, 
including studies on the effect of mixing soft waste with cotton, the effect of vibrating bobbins, the effect of different speeds and settings in processing, a comparison of two and three passages of drawing, and an improved method of ribbon lap preparation. Theoretical studies of machine interference have also been made and are being checked with the results of actual mill working. At present the quality control technique is being extended to chemical processing. The possibility of introducing acceptance sampling is also being explored. The Division maintains a computing section to analyse the data coming from various Divisions as well as from the quality-control sections of mills; it publishes a quality-control bulletin incorporating the data collected by the various quality-control sections in mills and the results of experiments carried out by them, and conducts classes for training technicians in statistical methods.

The Psychology Division has been concerned mainly with problems of attitudes, labour management relations, supervisory training, incentives, time-and-motion studies, the effect of physical working conditions on the health of workers and their efficiency, ete. A number of interesting results have been obtained in these various fields, some of which have found practical application on a large scale in mills. A project was conducted during 1950-51 in collaboration with Prof. Gardner Murphy, Unesco consultant to the Government of India, in order to study labour-management tension within the textile industry. As a result of this study, the need for supervisory training was emphasized and training-within-industry programmes were started in 1953 to fulfil this need with the technical assistance of the International Labour Organization. Thirtyone mills are participating at present, and in the short period of one year 2,884 supervisors have been trained. The three training-within-industry programmes have been translated into the Gujerati language so that a greater number of supervisors can participate in them. At the joint request of organized industry and labour, the Psychology Division has worked extensively on assessment of work loads in the various occupations of the industry and on applying the job evaluation methods for recommending a scientific wage structure.

Recently the newly established Liaison Division has taken over, from the research divisions, primary responsibility of maintaining close contacts with member mills and the quick translation of the Association's research into routine industrial practice.

With the completion of the first five years of the Association, the need for a properly balanced research programme covering both fundamental and applied problems has been increasingly felt. Such a programme, where fundamental and applied research would complement one another and constantly provide new ideas, has now been initiated. With technical assistance from Unesco, a project for the study of the nature of macromolecules has been started. An equilibrium centrifuge and gas adsorption apparatus have been set up. Some of the other fundamental problems in this programme are the preparation and properties of colloid solutions with special reference to spinning aids; the spectrophotometric, eolorimetric and chemical study of adsorption of substances on textiles; changes in the surface and mechanical properties and in the fine structure of textiles, caused by processes such as sizing, dyeing, mercerizing and finishing; the theory of tensile strength of yarns; the relation between structural geometry and mechanical properties of fabrics ; and morale and attitude surveys. Along with the national laboratories of India, the Ahmedabad Textile Industry's Research Association is playing a significant part in tackling the great and important problems which face India to-day.

\section{ABNORMAL PROPERTIES OF HISTONES FROM MALIGNANT CELLS}

\author{
BY DR. H. J. CRUFT, DR. C. M. MAURITZEN* \\ and Dr. E. STEDMAN, F.R.S.
}

Department of Biochemistry, University of Edinburgh

7 HE main object of this article is to give a brief description of a difference which has been observed to exist between the histones of malignant and normal cells. For an appreciation of the nature and significance of this difference, however, a knowledge of the properties and behaviour of histones from normal cells is required. It is therefore proposed, before describing and discussing the results obtained with the histones from cancer tissue, to summarize the pertinent aspects of our knowledge of these proteins, much of which has not hitherto been published.

\section{Basic Proteins of Cell Nuclei}

It has long been known that proteins with pronounced basic properties are present in the sperm heads of many fishes as well as in the nuclei of calves' thymocytes and of nucleated erythrocytes, and more recent work has shown that such proteins are, in fact, widely distributed in the nuclei of animal, and probably also of plant, cells where they constitute a considerable proportion, in some cases amounting to 30 per cent, of the dry weight of the nucleus. Two types of such proteins have been distinguished, namely, protamines and histones, the former of which seem to occur only in the sperm heads of certain fishes. The best known and most investigated of the protamines are salmine and clupeine, the basic proteins present in the sperm heads of the salmon and herring, respectively. Their properties fully justify their separate classification on chemical grounds, for they are distinguished from the histones in three respects : their salts form true solutions in water; no aromatic amino-acids enter into their composition; and they possess considerably stronger basic properties due to a higher content of basic amino-acids. It is not certain if all the basic proteins which have been termed protamines exhibit these properties, for there is little information available about them, while some doubt remains about the purity of the specimens originally examined.

While justified on chemical grounds, the classification of the basic proteins of cell nuclei into protamines and histones is not warranted physiologically, for a study of their distribution indicates that they are homologous proteins. Thus, so far as they have been examined, all fish sperm heads contain a basic protein. In the salmon and herring this is a protamine. On the other hand, in the cod it is a histone. Taken in conjunction with the fact that

\footnotetext{
* I.C.I. Research Fellow.
} 